\title{
Response competition: A major source of interference in a tactile identification task
}

\author{
PAUL M. EVANS \\ Willamette University, Salem, Oregon \\ and \\ JAMES C. CRAIG \\ Indiana University, Bloomington, Indiana
}

\begin{abstract}
Two experiments investigated the ability of subjects to identify a moving, tactile stimulus. In both experiments, the subjects were presented with a target to their left index fingerpad and a nontarget (also moving) to their left middle fingerpad. Subjects were instructed to attend only to the target location and to respond " 1 " if the stimulus moved either to the left or up the finger, and to respond " 2 " if the stimulus moved either right or down the finger. The results showed that accuracy was better and reaction times were faster when the target and nontarget moved in the same direction than when they moved in different directions. When the target and nontarget moved in different directions, accuracy was significantly better and reaction times were significantly faster when the two stimuli had the same assigned response than when they had different responses. The results provide support for the conclusion that movement information is processed across adjacent fingers to the level of incipient response activation, even when subjects attempt to focus their attention on one location on the skin.
\end{abstract}

A large body of evidence demonstrates that we are often unable to ignore irrelevant attributes of an attended stimulus. Perhaps the best known demonstration of this inability to restrict attention is the Stroop phenomenon (Stroop, 1935). Subjects are shown words that are printed in different colors of ink and instructed to name the color of the ink. The task is relatively simple unless the words are names of different colors. It is generally assumed that the highly practiced and automatic access of word meaning makes it difficult to pay attention only to a single attribute of the stimuli-the color of the ink (Neill, 1978; Proctor, 1978, 1981).

In addition to our limited ability to restrict processing to a single attribute of an attended stimulus, we are often unable to ignore irrelevant stimuli that appear in the same visual field as an attended target. In one study, subjects learned to move a lever to the right if a pattern was, for example, the letter $\mathrm{H}$ or the letter $\mathrm{G}$; they learned to move the lever to the left if the target was the letter $K$ or the letter I (C. W. Eriksen \& Hoffman, 1973). When the target patterns were flanked by nontargets (distractors), little interference was observed as long as the nontargets had the same learned response as the target (e.g., GHG).

This research was supported by Grant DC-00095 from the National Institutes of Health and was conducted while the first author was a visiting scholar in the Institute for the Study of Human Capabilities at Indiana University. The authors thank Roger P. Rhodes for his assistance in conducting these experiments. Reprint requests should be addressed to Paul M. Evans, Department of Psychology, Willamette University, Salem, OR 97301.
A significant amount of interference was observed, however, when the target and nontargets had different learned responses (e.g., HKH).

The results of the study by C. W. Eriksen and Hoffman (1973), together with the results of a number of additional studies, led C. W. Eriksen and Schultz (1979) to conclude that subjects are unable to restrict their attention to a single letter and that a flanking nontarget is processed to the level of incipient response activation. According to C. W. Eriksen and Schultz (1979), information about target and nontarget stimuli accumulates gradually in the visual system. As information accumulates, target and nontarget responses are primed. Interference occurs when conflicting responses are primed. Thus, significantly more interference is observed on responseincompatible trials than on response-compatible trials. If the interfering effect of flanking nontargets occurred primarily at an early stage of perceptual processing, then we would not expect the amount of interference observed to depend on experimentally defined response mapping (Bjork \& Murray, 1977; B. A. Eriksen \& C. W. Eriksen, 1974; C. W. Eriksen \& St. James, 1986; Estes, 1974; Miller, 1982; Rueckl, Suzuki, \& Yeh, 1991; St. James, 1991).

Our limited ability to restrict processing to a single stimulus is not restricted to visually presented stimuli. It has been known for some time that a tactile stimulus presented to one site on the skin may interfere with the ability to detect or identify a stimulus presented to another site on the skin (Cholewiak \& Craig, 1984; Craig, 1974; Gescheider, Herman, \& Phillips, 1970; Gilson, 1969; Sherrick, 1964; Sherrick \& Cholewiak, 1986; Snyder, 1977; Weisenberger, 1981). Whether these studies are grouped under 
the general rubric of "attention" or "masking," they demonstrate the inability of subjects to restrict processing to a specific docation on the skin.

In a recent study, Evans and Craig (1991) presented subjects with a target stimulus to the left index fingerpad. The target moved across the fingerpad either from left to right or from right to left. A nontarget stimulus presented to the adjacent fingerpad moved either in the same direction as the target or in the opposite direction. In spite of explicit instructions to the contrary, subjects appeared to be unable to focus their attention on the left index fingerpad and restrict processing to stimuli presented to that site. The direction of movement of the nontarget affected performance in a systematic fashion. Accuracy was higher, and reaction times were faster, when the nontarget and target moved in the same direction than when they moved in opposite directions.

Evans and Craig (1991) concluded that the effects they observed were not due to a momentary shift of attention to the nontarget site. Their results indicate that the spotlight of attention on the skin extends at least across adjacent fingers. The results do not, however, allow conclusions to be drawn about the locus of the interfering effect of a tactile nontarget. It is possible that interference $o c-$ curs with tactually presented stimuli at an early stage of perceptual processing. Estes (1972), for example, proposed that for visual stimuli, inputs to feature detectors undergo inhibitory interactions. When flanking nontargets and a target differ, more feature detectors are activated than when the nontargets and target are the same. Increasing the number of activated feature detectors increases the amount of inhibition, which results in decreased accuracy and increased reaction time (see also Bjork \& Murray, 1977). For tactile, spatial patterns, several studies of temporal masking have shown the importance of features in determining the amount of interference a masker produces. Maskers, presented to the same location as targets, cause more interference in target identification if they have features that are similar (but not identical) to those contained in the target (Craig, 1982; Craig \& Evans, 1987). Alternatively, it is possible that a tactile nontarget causes interference at a relatively late stage of perceptual processing. As with visual stimuli, a tactile nontarget may be processed to the level of incipient response activation. When the nontarget and target responses compete, accuracy is reduced and reaction times may increase. Finally, it is also possible that interference occurs both at an early and at a late stage of perceptual processing (Keren, O'Hara, \& Skelton, 1977).

In the present study, we investigated the locus of the interfering effect of a tactile nontarget by using a paradigm similar to that used by Eriksen and his colleagues. The results of the two experiments parallel those reported in the vision literature. For moving tactile stimuli, a nontarget appears to be processed with a target to the level of incipient response activation.

\section{EXPERIMENT 1}

In Experiment 1 , the subjects were trained to identify and categorize four tactile stimuli. The stimuli were vertical and horizontal bar-like patterns that appeared to move across the fingerpad (left, right, up, or down). Two of the stimuli (left and up) were assigned the response " 1 ." The remaining two stimuli (right and down) were assigned the response " 2 ." The target site was the left index fingerpad, and the subjects were instructed to categorize the stimulus presented to that site. A nontarget stimulus was presented to the left middle fingerpad at either the same time as the target or $500 \mathrm{msec}$ before the target onset.

The pairs of stimuli presented to the two fingerpads created three types of trials. On stimulus-compatible (SC) trials, the target and nontarget moved in the same direction and, of course, had the same response. On responsecompatible (RC) trials, the target and nontarget moved in different directions but were assigned the same response. On response-incompatible (RI) trials, the nontarget and target moved in different directions and were assigned different responses. The predictions were as follows: If the interfering effect of a tactile nontarget is located at an early stage of perceptual processing and is the result of inhibitory interactions among feature detectors, then we would expect performance to be best on SC trials (when the fewest number of feature detectors will be activated) and worst on RC and RI trials. More important, performance on RC and RI trials should be approximately equal because, in both cases, the same number of feature detectors will be activated. If, however, the interfering effect of a tactile nontarget is located at a relatively late stage of perceptual processing and is the result of competing nontarget and target responses, then we would expect performance to be best and approximately equal on SC and RC trials (the stimuli have identical responses) and worst on RI trials.

\section{Method}

\section{Subjects}

The subjects were 5 undergraduate students at Indiana University ( 4 females and 1 male). All of the subjects were paid employees of the laboratory and had participated in a number of related experiments prior to participating in the present study.

\section{Apparatus}

The apparatus consisted of two tactile arrays interfaced to a PDP $11 / 34$ computer. Each tactile array was similar to that used in the Optacon, a reading aid for the blind (Telesensory Systems, Inc.). The arrays are rectangular (11 mm wide and $27 \mathrm{~mm}$ high) and consist of 6 columns and 24 rows of blunt pins. Adjacent rows of pins are separated by $1.2 \mathrm{~mm}$, and adjacent columns are separated by $2.3 \mathrm{~mm}$. Only the top 18 rows of pins were used in the present study. Each pin can be addressed independently by the computer and vibrates at a frequency of approximately $230 \mathrm{~Hz}$ when activated.

The computer enables spatial stimuli to be generated on each tactile display for durations that are multiples of $4.35 \mathrm{msec}$. The computer also controls a visual display (used for instructions and feedback), 


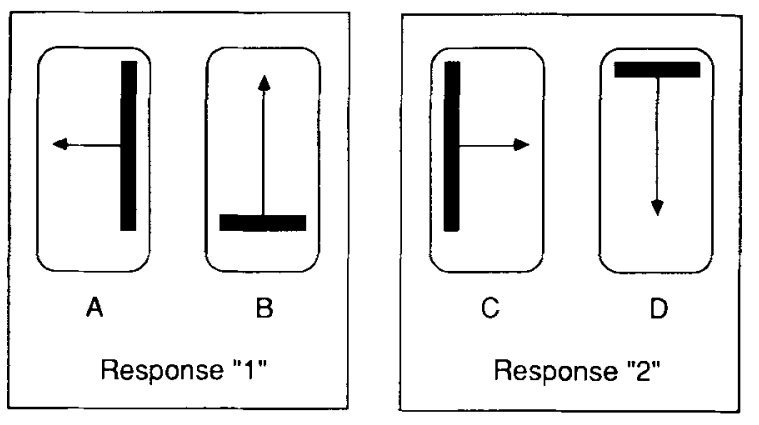

Figure 1. Illustrations of the four stimuli used in Experiments 1 and 2. Stimuli $A$ and $B$ were assigned the response " 1 ," and stimuli $C$ and D were assigned the response "2."

controls the presentation routine, collects subjects' responses, and records response latencies to the nearest millisecond (Craig, 1980, 1982).

\section{Stimuli}

The stimuli were vertical and horizontal bar-like patterns. Movement was simulated on each fingerpad by shifting the location of activated pins either in a column-by-column sequence or in a rowby-row sequence. To simulate movement across the fingerpad, column 1 (or column 6) of the tactile array was activated for $8.7 \mathrm{msec}$, followed by the activation of column 2 (or column 5) for $8.7 \mathrm{msec}$, and so on. To simulate movement up and down the fingerpad, rows 1,2 , and 3 (or rows 16,17 , and 18 ) of the tactile array were activated for $8.7 \mathrm{msec}$, followed by the activation of rows 4,5 , and 6 (or rows 13, 14, and 15) for $8.7 \mathrm{msec}$, and so on (see Figure 1). The total duration of each stimulus was $52 \mathrm{msec}$.

\section{Procedure}

The subjects were tested individually. Each subject sat with the left arm extended, with the left index fingerpad resting on one tactile array and the left middle fingerpad resting on the second tactile array. The subjects were told that they would be presented with tactile patterns that would appear to be moving. The patterns would appear to move from left to right (or vice versa) or from the top to the bottom of the display (or vice versa). The subjects' task was to focus attention on the index fingerpad and to identify the stimulus presented to that site. They were instructed to ignore the stimulus presented to the middle fingerpad. Two of the stimuli (left or up) were assigned the response " 1 ," and two of the stimuli (right or down) were assigned the response " 2 ." The subjects responded by pressing labeled buttons on a keypad with the index and middle fingers of their right hands. They were asked to respond as quickly as possible without sacrificing accuracy, and they were aware that their responses were being timed.

During the collection of pilot data, some subjects reported that stimuli presented to the display under the left middle finger felt less intense than stimuli presented to the display under the left index finger. To equate the perceived intensity of the stimuli presented on the two displays, the subjects adjusted the voltage applied to each display so that they could produce patterns that felt equally intense. The average setting for the right display was $49.5 \mathrm{~V}$; for the left display, it was $33 \mathrm{~V}$. In addition, the display positions were reversed for each subject on alternating daysthat is, the display used to present stimuli to the target location (the left index fingerpad) on Day 1 of testing was used to present stimuli to the nontarget location (the left middle fingerpad) on Day 2 of testing, and vice versa. The results, however, were essentially identical regardless of which display was used to present the target.
Each trial began with the subject pressing either one of the response keys. The nontarget stimulus was presented to the middle fingerpad $1 \mathrm{sec}$ later. The target stimulus was presented to the index fingerpad either at the same time as the nontarget or after a delay of $500 \mathrm{msec}$. Following the stimulus presentation, the subjects responded by pressing one of the two response keys. A correct response was followed by the word "CORRECT" appearing on the visual display for $500 \mathrm{msec}$. An incorrect response was followed by the word "WRONG' appearing on the visual display. Following the feedback routine, the subjects initiated the next trial by again pressing either one of the response keys. The subjects completed a total of six sessions.

Each experimental session lasted approximately $30 \mathrm{~min}$ and consisted of seven blocks of 50 trials. Each session began with one block of single-pattern identification trials. On the remaining six blocks of trials, the stimulus onset asynchrony (SOA) was varied randomly from trial to trial. Target and nontarget stimuli were chosen randomly on a trial-by-trial basis with no restrictions. Thus, a quarter of the trials were SC trials, a quarter were RC trials, and half were RI trials. The subjects wore headphones through which white noise was presented to eliminate auditory cues produced by the tactile arrays.

\section{RESULTS}

\section{Accuracy}

All subjects showed a similar pattern of results. Figure 2 shows the percentage of correct responses, averaged across subjects, for each of the three trial types (SC, $R C$, and RI). The results of a two-way, repeated measures analysis of variance (ANOVA) revealed no effect of SOA $[F(1,4)=4.59, p>.05]$, a main effect of trial type $[F(2,8)=16.55, p<.01]$, and an interaction between SOA and trial type $[F(2,8)=10.26, p<.01]$. At 0 -msec SOA, performance was best when the target and nontarget moved in the same direction (SC trials, 93\%), worst when the target and nontarget moved in different directions and were assigned different responses (RI trials, $78 \%$ ), and of intermediate value when the target and nontarget were different but assigned the same response (RC trials, 89\%). Planned comparisons showed that performance on the SC

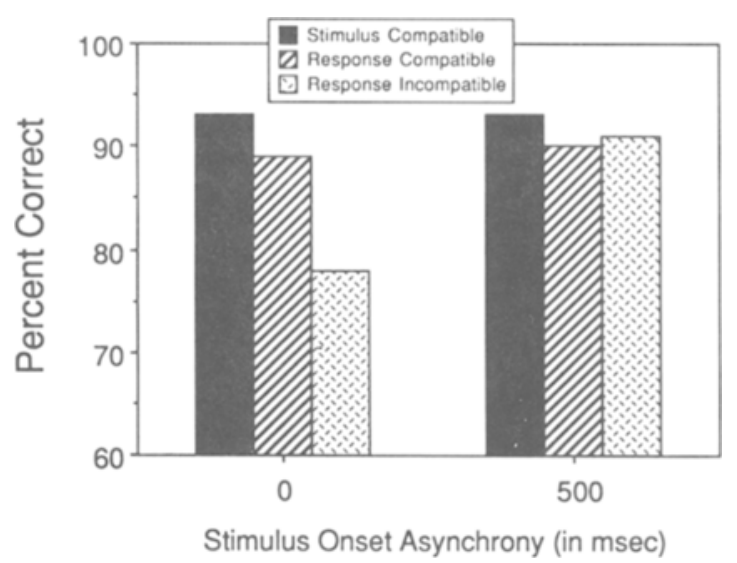

Figure 2. Percent correct target identification for each trial type (stimulus-compatible, response-compatible, and response-incompatible) as a function of the time between the target stimulus and the nontarget stimulus (stimulus onset asynchrony). 


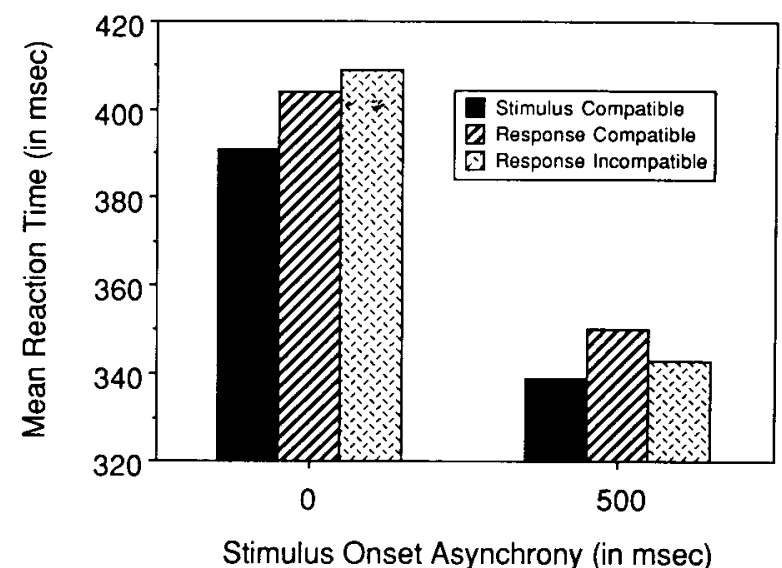

Figure 3. Mean reaction time (correct trials) for each trial type as a function of stimulus onset asynchrony.

and RC trials was statistically equivalent (average $=91 \%$ ) and significantly different from that observed on RI trials. At 500 -msec SOA, performance was statistically equivalent for all three trial types (average $=92 \%$ ). Singlepattern performance averaged $93 \%$.

\section{Reaction Times}

Reaction times less than $150 \mathrm{msec}$ or greater than $1,000 \mathrm{msec}$ accounted for less than $0.3 \%$ of the total trials and were excluded from subsequent analyses. Mean reaction times were calculated for correct responses and averaged across subjects. The results of a two-way, repeated measures ANOVA showed a main effect of SOA $[F(1,4)$ $=18.58, p<.02]$, a main effect of trial type $[F(2,8)$ $=10.01, p<.05]$, and no interaction between SOA and trial type $[F(2,8)=1.42, p>.05]$. The results are shown in Figure 3. Averaged across the three trial types, correct responses were significantly faster at 500-msec SOA than at 0 -msec SOA (344 vs. $401 \mathrm{msec}-$ a difference of $57 \mathrm{msec}$ ). Evans and Craig (1991) also reported that overall reaction times decreased as SOA was increased, an effect they attributed to a "general alerting reaction" (Bertelson, 1967; Posner \& Boies, 1971). When the nontarget preceded the target by $500 \mathrm{msec}$, its onset may have acted as a warning signal, enabling the subject to better prepare for the arrival of the target.

At 0-msec SOA, correct responses were fastest when the nontarget and target moved in the same direction (SC trials, $391 \mathrm{msec}$ ), slowest when the nontarget and target moved in different directions and were assigned different responses (RI trials, $409 \mathrm{msec}$ ), and of intermediate value when the nontarget and target moved in different directions and were assigned the same response (RC trials, $404 \mathrm{msec}$ ). Planned comparisons revealed that responses were significantly faster on SC trials than on RC trials or RI trials. At 500-msec SOA, reaction times were statistically equivalent for the three trial types.

\section{Discussion}

The results of Experiment 1 replicate and extend those reported by Evans and Craig (1991). First, accuracy was better, and reaction times were faster, when the target and nontarget moved in the same direction than when they moved in different directions. Second, when the target and nontarget did move in different directions, target performance was interfered with when the target and nontarget had different responses. This latter result parallels that reported in the vision literature and indicates that both the target and the nontarget were being processed to the level of incipient response activation. The fact that the effect disappears at 500-msec SOA suggests that once the nontarget has been processed, it no longer competes with the processing of the target stimulus.

That subjects can choose the correct response most of the time indicates, of course, that they are able to differentially attend to two adjacent sites on the skin. Clearly, however, the association between a specific response and a specific location on the skin is not a perfect one. A target may be well perceived, and its response primed, but the activation of the response may be slowed if a conflicting response is also primed (Neill, 1978; Proctor, 1978, 1981; Stroop, 1935). On occasion, when the association between a specific response and a specific spatial location is particularly weak, subjects may respond incorrectly.

The fact that responses were faster on SC trials than on RC trials, together with the finding that responses were slightly more accurate on SC trials than on RC trials, suggests that a portion of the interfering effect of a tactile nontarget is located at an early stage of perceptual processing. The small disadvantage for RC trials compared with SC trials may be due to increased inhibition when the target and nontarget stimuli activate different feature detectors (Estes, 1972). Experiment 2 addressed this issue.

\section{EXPERIMENT 2}

The results of Experiment 1 indicate that a tactile nontarget is processed to the level of response activation. The accuracy data and reaction time data suggest that a major portion of the interfering effect of a tactile nontarget is the result of competition between conflicting responses. The results of Experiment $1 \mathrm{do}$, however, provide some evidence that a portion of the interfering effect of a tactile nontarget is due to interactions at an early stage of perceptual processing. Recall that there was a small (but significant) difference between reaction times on $\mathrm{SC}$ and RC trials. In Experiment 2, we attempted to increase the magnitude of the difference between SC and RC trials. First, we manipulated the intensities of the nontarget and target so that the perceived intensity of the nontarget was 2.5 times that of the target. The assumption we made was that increasing the intensity of the nontarget relative to that of the target would lead to an increase in the amount 
of interference on those trials in which the target and nontarget differed. Second, and in a separate set of measurements, we followed the onset of the target with a masking stimulus. The assumption made here was that the masker would degrade the representation of the target relative to that of the nontarget and thus increase the interfering effect of the nontarget.

\section{Method}

Experiment 2 was conducted in two parts. Five subjects participated in Part 1 ( 3 females and 1 male, all of whom had participated in Experiment 1, plus 1 additional female). Five subjects participated in Part 2 ( 2 female subjects from Part 1 plus 3 additional female subjects).

The general procedural details for both parts of Experiment 2 were identical to those of Experiment 1, with the following exceptions. In Part 1, "Masking," the voltages for the displays were set at the same levels as in Experiment 1. In this case, however, the target stimulus was followed by the onset of a masking stimulus. The masker consisted of turning on the top 18 rows of stimulators in the display for $52 \mathrm{msec}$ (Craig, 1982). The masker followed the onset of the target by $78 \mathrm{msec}$. In Part 2, "Intensity Manipulation," the voltage for the stimulators of the nontarget display was 3 times higher than that for the stimulators of the target display ( $49.5 \mathrm{~V}$ vs. $16.5 \mathrm{~V}$ ). The subjects estimated that with this change in voltage, stimuli presented on the nontarget display felt 2.5 times more intense than those presented on the target display. Also, we included an additional SOA condition in Part 2 of Experiment 2: The nontarget preceded the onset of the target by $100 \mathrm{msec}$. In both parts of Experiment 2, the target site was the left index fingerpad. The subjects completed a total of six experimental sessions for each part.

\section{Results}

\section{Masking}

Accuracy. Performance with the masker present was, as expected, poorer than that observed in Experiment 1. Single-pattern performance, that is, performance without the nontarget but with the backward masker, was $84 \%$, a reduction of $9 \%$ from that observed in Experiment 1 . The results of an ANOVA showed a main effect of SOA

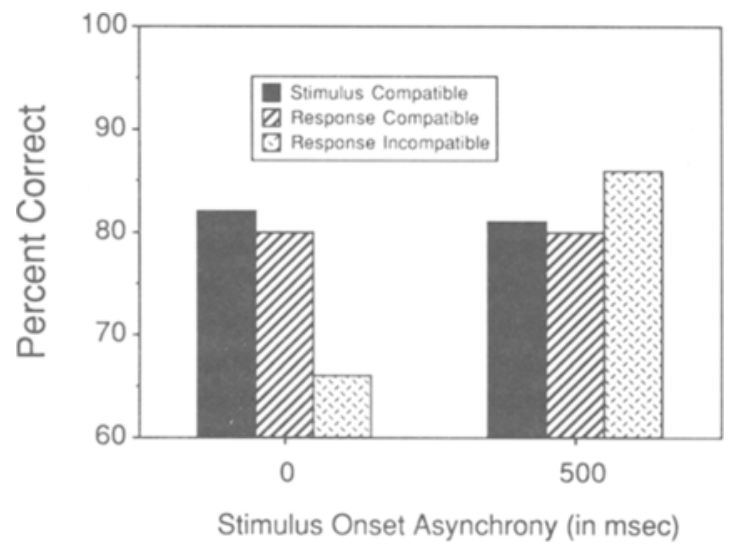

Figure 4. Percent correct identification for each trial type as a function of stimulus onset asynchrony. The target was followed by a masking stimulus.

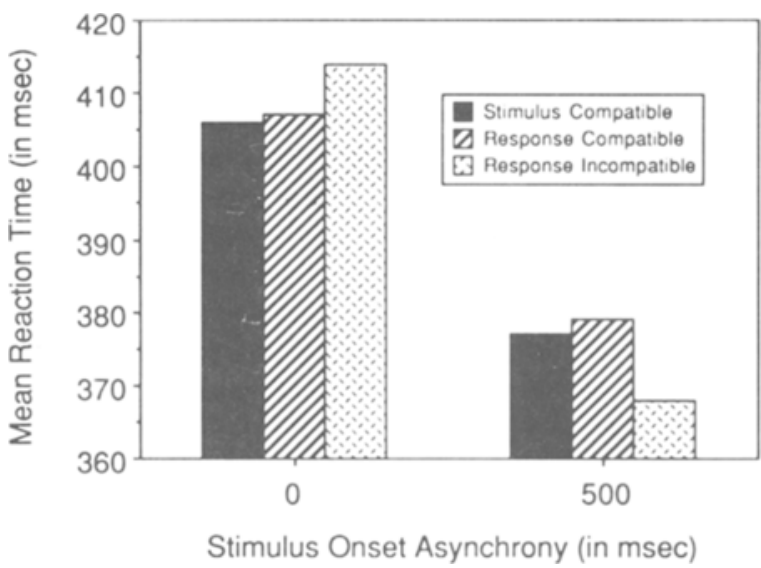

Figure 5. Mean reaction time (correct trials) for each trial type as a function of stimulus onset asynchrony. The target was followed by a masking stimulus.

$[F(1,4)=7.53, p<.05]$, a main effect of trial type $[F(2,8)=10.31, p<.01]$, and a significant interaction between SOA and trial type $[F(2,8)=5.81, p<.05]$. At 0 -msec SOA, performance was statistically equivalent on SC and RC trials (82\% and $80 \%$, respectively), and performance dropped significantly on RI trials $(66 \%)$ ). At 500 -msec SOA, performance was statistically equivalent for the three trial types (average $=83 \%$ ). The results are shown in Figure 4.

Reaction times. Figure 5 shows mean reaction times (correct trials) for the three trial types at each SOA. An ANOVA revealed a main effect of SOA $[F(1,4)=17.42$, $p<.02]$, no main effect of trial type $[F(2,8)=0.18$, $p>.05]$, and an interaction between SOA and trial type $[F(2,8)=9.12, p<.01]$. As observed before, overall reaction times decreased with increasing SOA. Reaction times were fastest on SC trials, slowest on RI trials, and of intermediate value on RC trials (Figure 5). In the present case, however, none of the differences was statistically significant. The pattern of results, however, was very similar to that observed in Experiment 1.

\section{Intensity Manipulation}

Accuracy. The results are shown in Figure 6. An ANOVA revealed a main effect of $\operatorname{SOA}[F(2,8)=11.12$, $p<.01]$, a main effect of trial type $[F(2,8)=8.22, p<$ $.02]$, and an interaction between these two factors $[F(4,16)$ $=7.07, p<.01]$. At 0 -msec SOA, performance was best when the target and nontarget were the same (SC trials, $92 \%$ ), worst when the target and nontarget were different and assigned different responses (RI trials, 65\%), and of intermediate value when the target and nontarget were different but assigned the same response (RC trials, $86 \%$ ). Statistically, performance on SC and RC trials was, as in Experiment 1, equivalent (average $=89 \%$ ) and significantly different from that obtained on RI trials. At 100 msec SOA, a similar pattern of results was obtained, with the largest difference observed between performance on RC and RI trials, a statistically significant difference of 


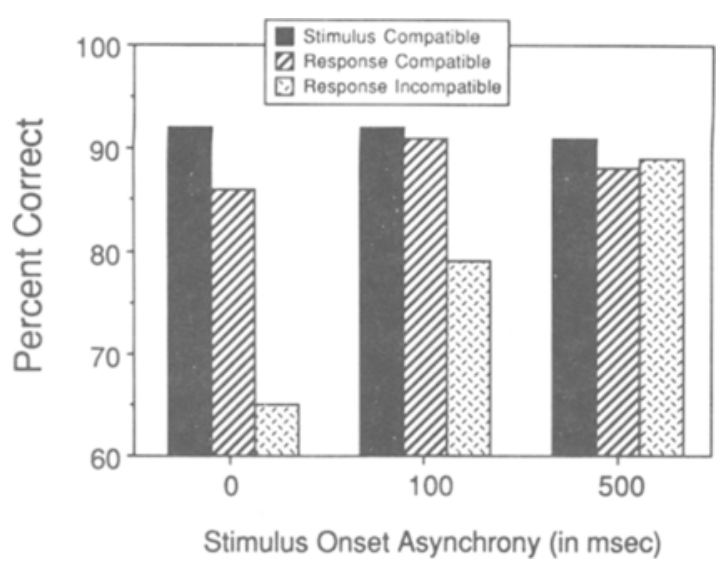

Figure 6. Percent correct identification for each trial type as a function of stimulus onset asynchrony. The nontarget was presented at an intensity level judged to be 2.5 times that of the target.

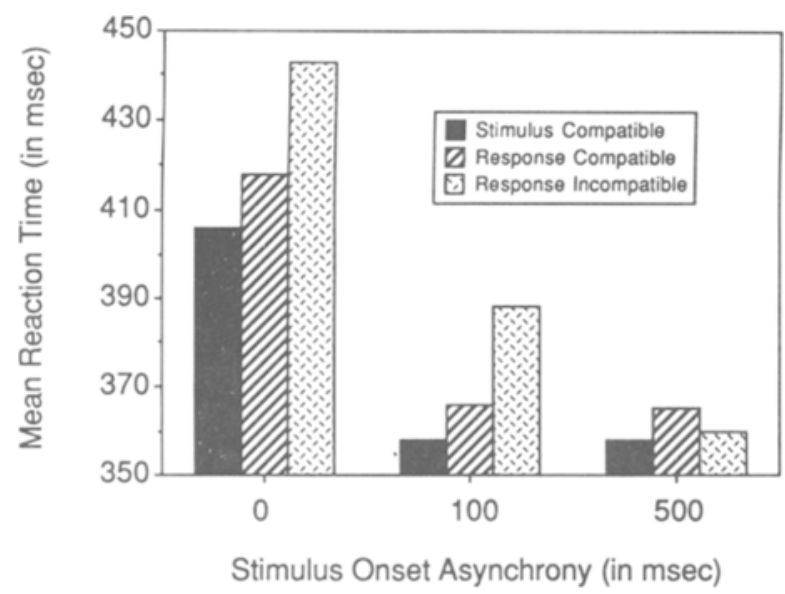

Figure 7. Mean reaction time (correct trials) for each trial type as a function of stimulus onset asynchrony. The nontarget was presented at an intensity level judged to be 2.5 times that of the tanget.

$12 \%$. In comparison, the difference between performance on SC and RC trials was only $1 \%$. At 500 -msec SOA, performance was equivalent for all three trial types and averaged $89 \%$. Single-pattern performance averaged $93 \%$.

Reaction times. Figure 7 shows the mean reaction times (correct trials) for the three trial types as a function of SOA. An ANOVA showed a main effect of SOA $[F(2,8)$ $=26.86, p<.001]$, a main effect of trial type $[F(2,8)$ $=16.36, p<.01]$, and a significant interaction between these two factors $[F(4,16)=11.69, p<.001]$. At 0 -msec SOA, reaction times were fastest when the target and nontarget were the same (SC trials, $406 \mathrm{msec}$ ), slowest when the target and nontarget were different and assigned different responses (RI trials, $443 \mathrm{msec}$ ), and of intermediate value when the target and nontarget were different but assigned the same response (RC trials, $418 \mathrm{msec}$ ). Statistically, performance on SC and RC trials was equivalent (average $=412 \mathrm{msec}$ ) and significantly different from that observed on RI trials. At 100 -msec SOA, reaction times were significantly faster on SC and RC trials than on RI trials. Reaction times were statistically equivalent on SC and RC trials, and for all trial types at 500-msec SOA. Overall, reaction times decreased with increasing SOA, as observed in Experiment 1.

\section{Discussion}

The results of Experiment 2 are similar, in all respects, to those of Experiment 1. Accuracy was better on SC and RC trials than on RI trials. Correct responses were faster on SC and RC trials than on RI trials. The results reinforce the conclusion that a moving, tactile nontarget is processed to the level of incipient response activationonly when the target and nontarget responses were different was accuracy significantly reduced and reaction times significantly increased.

Performance on SC and RC trials was statistically equivalent. Neither degrading the target representation nor making the nontarget more intense than the target resulted in an increase in the difference between SC and RC trials. Indeed, although the pattern of results was similar to that observed in Experiment 1, the magnitude of what we attribute to response competition was, if anything, enhanced. The absence of a significant difference between performance on SC and RC trials would seem to reduce the role of inhibitory interactions between feature detectors as a factor involved in the interfering effect of a tactile nontarget. It should be noted, however, that we have consistently observed a small difference between performance on SC and RC trials, suggesting that the difference, although small, is a real one. Although speculative, it is possible that there is something special about the processing of physically identical stimuli presented to the skin. Clearly, however, the major difference observed in Experiment 2, as was also observed in Experiment 1, was between performance on RC and RI trials. The major portion of the interfering effect of a moving, tactile nontarget appears to be a result of response competition.

The results of Experiment 2 also indicate the robustness of the response-competition findings. In Experiment 1 , we obtained the effect with target and nontarget stimuli of equal perceived intensity. If we had found that this was a necessary condition to obtain the effect, the generality of the conclusions would be limited. Certainly in haptic exploration of objects, tactile patterns arriving at the fingerpads will differ in intensity from one another or be poorly represented in some way. The present results suggest that response competition could play an important role in tasks involving multiple sites of tactile stimulation and multiple stimuli.

\section{GENERAL DISCUSSION}

The results of the present study support two major conclusions. First, the spotlight of attention on the skin extends at least across adjacent fingers: The subjects were apparently unable to focus their attention on one finger, 
the target site, and exclude processing the stimulation delivered to a second finger, the nontarget site. Second, a moving, tactile nontarget is processed to the level of incipient response activation: When the nontarget and target moved in different directions, performance was worse when they were assigned different responses than when they were assigned the same response.

The fact that the spotlight of attention on the skin extends at least across adjacent fingers raises the question of whether the effects reported here would be obtained if the spatial distance between the target and nontarget was systematically varied. Evans and Craig (1991) found that when a target was presented to the right middle fingerpad (contralateral to the nontarget), target performance was not affected by the presence of the nontarget. These measurements indicate that the attentional spotlight on the skin does not extend across the hands. Whether the effects reported here would diminish as the spatial separation between the target and nontarget is increased on the same hand is an empirical question. In the vision literature, estimates of the size of the visual-attention spotlight have yielded values of approximately $1^{\circ}$ of visual angle, at least for unrelated target and nontarget letters (Driver \& Baylis, 1991; C. W. Eriksen \& Hoffman, 1973; C. W. Eriksen \& Schultz, 1979; Gathercole \& Broadbent, 1987). At this point, we have no comparable estimates of the size of the tactile-attention spotlight.

The fact that flanking nontarget stimuli are processed to the level of incipient response activation, both visually and, as demonstrated in the present study, tactually, has been taken as evidence for a late-selection model of attention (e.g., Duncan, 1980; Miller, 1987; Shiffrin \& Geisler, 1973; Van der Heijden, 1981). By this view, all stimuli are automatically processed fully, with selection taking place after this analysis is complete. It should be noted, however, that a response-competition effect is consistent with one version of an early-selection model (Broadbent, 1982; Treisman, 1964). According to the attenuation model of attention, an early-selection filter does not completely prevent processing of nonattended stimuli. Rather, stimuli presented to a nonattended site are attenuated-that is, they receive less processing than stimuli presented to an attended site. Although the present study was not designed to investigate early- versus late-selection models of attention, the results appear to rule out a model of attention that proposes no processing of movement information of nonattended tactile stimuli (Johnston \& Dark, 1982).

\section{REFERENCES}

BeRTELSON, P. (1967). The time course of preparation. Quarterly Journal of Experimental Psychology, 19, 272-279.

Bjork, E. L., \&urRay, J. T. (1977). On the nature of input channels in visual processing. Psychological Review, 84, 472-484.

BROADBENT, D. E. (1982). Task combination and selective intake of information. Acta Psychologica, 50, 253-290.

Cholewiak, R. W., C Craig, J. C. (1984). Vibrotactile pattern recognition and discrimination at several body sites. Perception \& Psychophysics, 35, 503-514.
Craig, J. C. (1974). Vibrotactile difference thresholds for intensity and the effect of a masking stimulus. Perception \& Psychophysics, 15, 123-127.

Craig, J. C. (1980). Modes of vibrotactile pattern generation. Journal of Experimental Psychology: Human Perception \& Performance, 6. $151-166$.

Craig, J. C. (1982). Vibrotactile masking: A comparison of energy and pattern maskers. Perception \& Psychophysics, 31, 523-529.

Craig, J. C., Evans, P. M. (1987). Vibrotactile masking and the persistence of tactual features. Perception \& Psychophysics, 42, 309-317.

Driver, J., BAyırs, G. C. (1991). Target-distractor separation and feature integration in visual attention to letters. Acta Psychologica, 76, 101-119.

DUNCAN, J. (1980). The locus of interference in the perception of simultaneous stimuli. Psychological Review, 87, 272-300.

EriksEN, B. A., ERIKSEN, C. W. (1974). Effects of noise letters upon the identification of a target letter in a nonsearch task. Perception \& Psychophysics, 16, 143-149.

Eriksen, C. W., Hofrman, J. E. (1973). The extent of processing of noise elements during selective encoding from visual displays. Perception \& Psychophysics, 14, 155-160.

ERIKSEN, C. W., Schultz, D. W. (1979). Information processing in visual search: A continuous flow conception and experimental results. Perception \& Psychophysics, 25, 249-263.

Eriksen, C. W., St. JAmes, J. D. (1986). Visual attention within and around the field of focal attention: A zoom lens model. Perception \& Psychophysics, 40, 225-240.

ESTES, W. K. (1972). Interactions of signal and background variables in visual processing. Perception \& Psychophysics, 12, 278-286.

EsTes, W. K. (1974). Redundancy of noise elements and signals in visual detection of letters. Perception \& Psychophysics, 16, 53-60.

Evans, P. M., Craig, J. C. (1991). Tactile attention and the perception of moving tactile stimuli. Perception \& Psychophysics, 49, 355-364.

Gathercole, S. E., \& Broadbent, D. E. (1987). Spatial factors in visual attention: Some compensatory effects of location and time of arrival of nontargets. Perception, 16, 433-443.

Gescheider, G. A., Herman, D. D., \& Phillips, J. N. (1970). Criterion shifts in the measurement of tactile masking. Perception \& Psychophysics, 8, 433-436.

GILsoN, R. D. (1969). Vibrotactile masking: Some spatial and temporal aspects. Perception \& Psychophysics, 5, 176-180.

JohnSTON, W. A., DARK, V. J. (1982). In defense of intraperceptual theories of attention. Joumal of Experimental Psychology: Human Perception \& Performance, 8, 407-421.

Keren, G., O'HARA, W. P., \& Skelton, J. M. (1977). Level of noise processing and attentional control. Journal of Experimental Psychology: Human Perception \& Performance, 3, 653-664.

MiLLER, J. (1982). Effects of noise letters on decisions: Discrete or continuous flow of information? Perception \& Psychophysics, 31, 227-236.

MiLleR,' J. (1987). Priming is not necessary for selective-attention failures: Semantic effects of unattended, unprimed letters. Perception \& Psychophysics, 41, 419-434.

NEILL, W. T. (1978). Decision processes in selective attention: Response priming in the Stroop color-word task. Perception \& Psychophysics, 23, 80-84.

Posner, M. I., \& Boles, S. J. (1971). Components of attention. Psychological Review, 78, 391408.

Proctor, R. W. (1978). Sources of color-word interference in the Stroop color-naming task. Perception \& Psychophysics, 23, 413-419.

Proctor, R. W. (1981). A unified theory for matching-task phenomena. Psychological Review, 88, 291-326.

Rueckl, J. G., Suzuki, S., \& Yeh, S. (1991). On the locus of redundancy effects in a letter-detection task. Perception \& Psychophysics, 49, 412-421.

SHERRICK, C. E. (1964). Effects of double simultaneous stimulation of the skin. American Journal of Psychology, 77, 42-53.

Sherrick, C. E., Cholewiak, R. W. (1986). Cutaneous sensitivity. In K. R. Boff, L. Kaufman, \& J. P. Thomas (Eds.), Handbook of perception and human performance: Sensory processes and perception (pp. 12-1-12-58). New York: Wiley. 
Shifrrin, R. M., GeISler, W. A. (1973). Visual recognition in a theory of information processing. In R. L. Solso (Ed.), Contemporary issues in cognitive psychology; The Loyola symposium (pp. 53-101). Washington, DC: Winston.

SNYDER, R. E. (1977). Vibrotactile masking: A comparison of psychophysical procedures. Perception \& Psychophysics, 22, 471-475.

ST. JAMES, J. D. (1991). Observations on the microstructure of response conflict. Perception \& Psychophysics, 48, 517-524.

STROOP, J. R. (1935). Studies of interference in serial verbal reactions. Journal of Experimental Psychology, 18, 643-662.
Treisman, A. M. (1964). Monitoring and storage of irrelevant messages in selective attention. Joumal of Verbal Learning \& Verbal Behavior, 3, 449-459.

VAN DER Heuden, A. H. C. (1981). Short-term visual information forgetting. London: Routledge \& Kegan Paul.

WeISENBERGER, J. M. (1981). Tactile pattem similarity. Unpublished doctoral dissertation, Indiana University, Bloomington.

(Manuscript received June 27, 1991; revision accepted for publication September 4, 1991.) 